\title{
КОРПОРАТИВНОЕ УПРАВЛЕНИЕ РОССИЙСКИХ КОМПАНИЙ В УСЛОВИЯХ ЗАПАДНЫХ САНКЦИЙ
}

\author{
(c) 2019 Покрамович Ольга Викторовна \\ кандидат экономических наук, доцент кафедры менеджмента и информационных технологий \\ Курский филиал Финансового университета при Правительстве Российской Федерации, \\ Россия, Курск \\ E-mail: 81pokrov@mail.ru
}

В статье рассматриваются некоторые последствия внесения российских компаний в антироссийский санкционный список в период 2016-2018 гг. Речь идет о санкциях в качестве факторов, ухудшающих перспективу развития национальных промышленных гигантов. Приводятся статистические данные, описывающие их. Упоминается возможность использования антироссийских санкций во благо ускорения роста национальной экономики при условии переориентации российских компаний с внешних факторов их развития на внутренние, которые связаны с факторами инклюзивного развития национальной экономики. Последнее может быть реализовано лишь при условии формировании адекватной институциональной среды в России для деятельности экономических агентов.

Ключевые слова: негативное воздействие западных санкций, состояние российских компаний из санкционного списка, переориентация национальных компаний на внутренние факторы развития.

Внешние экономические условия долгосрочного развития российских компаний неопределенны, что в значительной степени обусловлено геополитическими угрозами, представленными, в частности, антироссийскими санкциями [4]. По мнению Банка России (ЦБР), введенные в 2014-2019 гг. западные санкции в отношении России в ближайшие несколько лет сохранятся. Эта проблема усугубляется тем, что российская экономика остается зависимой от спроса на мировых рынках нефти, стоимость которой влияет не только на экспорт, но и на привлекательность российских активов для иностранных инвесторов [5]. В базовом прогнозе ЦБ ориентируется на падение мировых цен на нефть с $\$ 70 / б а р р$. в 2020 г. до \$55/барр. - в 2021 г. [6].

Возобновление темпов прироста российской экономики до $2 \%$ в год прогнозируется, начиная с 2020 г., что будет сопровождаться дальнейшим снижением ЦБР ключевой ставки, смягчением условий кредитования, а также активным инвестированием государством национальных проектов. По прогнозам Министерства экономического развития, по итогам 2019 г. прирост ВВП может составить 1,3\%, а к 2021 г. он должен увеличиться до 3\% в год.

По мнению ряда экспертов, ключевые риски для развития национальных компаний в долгосрочной перспективе обусловлены тем, что в случае расширения антироссийские санкции способны генерировать экономическую рецессию в стране [8].

По оценкам экспертов Аналитического кредитного рейтингового агентства (АКРА), уже действующие западные санкции сказались на интересах крупных государственных банков, которые сконцентрировали у себя около 54\% совокупных активов национальных банков, на положении нефтегазовых компаний, которые обеспечивают 95\% общей выручки нефтегазовой промышленности, на перспективах развития почти всех предприятий российского ВПК [2]. В целом только санкции США сказались на положении более чем 400 российских финансовых и нефинансовых организаций (табл. 1).

Введенные санкции определенно отразились на инвестиционном климате в России, ухудшив структуру долгов как финансовых, так и нефинансовых организаций, которые были включены в санкционный список. Российским компаниям пришлось увеличивать долю долга и облигаций в рублевом эквиваленте, а банкамускоренно сокращать долю облигаций, которые были номинированы в долларах и евро [3, с.29]. Такое сокращение присутствия западных инвесторов в ресурсах российских компаний быстро замещалось растущими кредитами с финансовых рынков азиатских стран. 
Таблица 1.Крупнейшие российские компании и банки, в отношении которых действуют секторальные (SSIlist) или блокирующие (SDNlist) санкции США

\begin{tabular}{|c|c|c|c|c|c|c|c|c|}
\hline \multicolumn{8}{|c|}{ Компаниям и гражданам США запрещается: } & \multirow[b]{2}{*}{$\begin{array}{c}\text { Прочие } \\
\text { операции + } \\
\text { заморозка } \\
\text { активов } \\
\text { санкцион- } \\
\text { ных компа- } \\
\text { ний в США }\end{array}$} \\
\hline & & Компания & $\begin{array}{c}\text { предостав- } \\
\text { ление фи- } \\
\text { нансирова- } \\
\text { ния, а также } \\
\text { прочие } \\
\text { операции с } \\
\text { новым дол- } \\
\text { гом сроком } \\
\text { более } 14 \\
\text { дней }\end{array}$ & $\begin{array}{c}\text { предостав- } \\
\text { ление фи- } \\
\text { нансирова- } \\
\text { ния, а также } \\
\text { прочие } \\
\text { операции с } \\
\text { новым дол- } \\
\text { гом сроком } \\
\text { более } 30 \\
\text { дней }\end{array}$ & $\begin{array}{c}\text { предостав- } \\
\text { ление фи- } \\
\text { нансирова- } \\
\text { ния, а также } \\
\text { прочие } \\
\text { операции с } \\
\text { новым дол- } \\
\text { гом сроком } \\
\text { более 60 } \\
\text { дней }\end{array}$ & $\begin{array}{c}\text { Операции } \\
\text { с новыми } \\
\text { акциями } \\
\text { (инвести- } \\
\text { ции в них) }\end{array}$ & $\begin{array}{c}\text { Экспорт и } \\
\text { реэкспорт } \\
\text { товаров, ус- } \\
\text { луг или тех- } \\
\text { нологий для } \\
\text { поддержки } \\
\text { разработки } \\
\text { и добычи }\end{array}$ & \\
\hline \multirow{12}{*}{$\begin{array}{l}\ddot{n} \\
\ddot{\mathscr{\omega}}\end{array}$} & \multirow{5}{*}{ 卺 } & ПАО Сбербанк & + & + & + & + & & \\
\hline & & Груаав ВТБ & + & + & + & + & & \\
\hline & & $\begin{array}{l}\text { АО «Россельхоз- } \\
\text { банк» }\end{array}$ & + & + & + & + & & \\
\hline & & Внешэкономбанк & + & + & + & + & & \\
\hline & & Банк ГПБ (AO) & + & + & + & + & & \\
\hline & \multirow{7}{*}{ 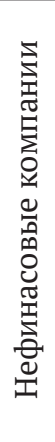 } & ПАО «Газпром» * & & & & & + & \\
\hline & & $\begin{array}{l}\text { ПАО «HK Po- } \\
\text { снефть» }\end{array}$ & & & + & & + & \\
\hline & & $\begin{array}{l}\text { ОАО «Сургутне- } \\
\text { фтегаз» }\end{array}$ & & & & & + & \\
\hline & & ПАО «НОВАТЕК» & & & + & & & \\
\hline & & ПАО «ЛУКОЙЛ» & & & & & + & \\
\hline & & $\begin{array}{l}\text { ПАО «Транс- } \\
\text { нефть» }\end{array}$ & & & + & & & \\
\hline & & ГК «Ростех» ** & & + & + & & & \\
\hline \multirow{13}{*}{$\begin{array}{l}\check{n} \\
\ddot{z} \\
\ddot{n}\end{array}$} & \multirow{5}{*}{ 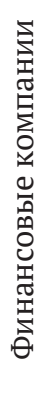 } & АО «СМП Банк» & + & + & + & + & + & + \\
\hline & & РНКБ Банк (ПАО) & + & + & + & + & + & + \\
\hline & & $\begin{array}{l}\mathrm{AO} \ll \mathrm{AБ} \ll \mathrm{POC}- \\
\text { СИЯ» }\end{array}$ & + & + & + & + & + & + \\
\hline & & Volga Group & + & + & + & + & + & + \\
\hline & & $\begin{array}{l}\text { ООО «ЛАДОГА } \\
\text { МЕНЕДЖМЕНТ» }\end{array}$ & + & + & + & + & + & + \\
\hline & \multirow{8}{*}{ 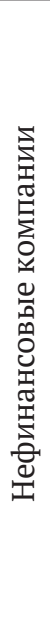 } & $\begin{array}{l}\text { ГК «Базовый } \\
\text { элемент» }\end{array}$ & + & + & + & + & + & + \\
\hline & & ГК «Ренова» & + & + & + & + & + & + \\
\hline & & $\begin{array}{l}\text { ПАО «Силовые } \\
\text { машины» }\end{array}$ & + & + & + & + & + & + \\
\hline & & $\begin{array}{l}\text { АО «Строй- } \\
\text { трансгаз» }\end{array}$ & + & + & + & + & + & + \\
\hline & & $\begin{array}{l}\text { ООО «АВИА } \\
\text { ГРУПП» }\end{array}$ & + & + & + & + & + & + \\
\hline & & ООО «Трансойл» & + & + & + & + & + & + \\
\hline & & $\begin{array}{l}\text { АО «НПК «Урал- } \\
\text { вагонзавод» }\end{array}$ & + & + & + & + & + & + \\
\hline & & $\begin{array}{l}\text { АО «Объеденная } \\
\text { судостроитель- } \\
\text { ная корпорация» }\end{array}$ & + & + & + & + & + & + \\
\hline
\end{tabular}

Источник: US Treasury Department (OFAC Sanctions list), AKPA

* «В отношении ПАО «Газпром нефть» помимо запрета на экспорт и реэкспорт товаров, услуг или технологий (для поддержки разработки и добычи) также действует запрет на привлечение долгового финансирования. Некоторые дочерние компании ПАО «Газпром» находятся в SDNlist (например, ОOО «Газпром бурение»).

** Некоторые дочерние компании находятся в SDNlist, например, АО «Концерн Калашников», «НПО Базальт», АО «Концерн Радиоэлектронные технологии» [2]». 
В результате, общий долг российских компаний, попавших под западные санкции, в апреле 2018 г. составлял почти 1,5 трлн. руб.: из них $12 \%$ были размещены в валютных облигациях, а 30\% - в финансовых инструментах, номинированных в рублях. На начало 2019 г. санкции коснулись 57\% долга нефинансовых организаций и $16 \%$ совокупного долга финансовых компаний. Причем на них распространены блокирующие санкции, поэтому в ближайшей перспективе структура их долга будет существенно скорректирована.

В итоге западные санкции негативно отразились на инвестиционном климате в стране, внеся свою лепту в генерирование факторов рецессии в российской экономике в 2014-2016 гг. Однако уже по результатам 2017 г. в целом совокупная консолидированная выручка национальных компаний и коммерческих банков из санкционного списка достигла 30 трлн. руб., а их вклад в ВВП оценивался в 20-21\%.

Последние 2018 года санкции оказали самое сильное воздействие на финансовое положение российских компаний, поскольку они носили блокирующий характер. С их помощью (SDNlist) США запрещали всевозможные взаимодействия российских компаний с экономическими агентами из США. Однако их негативные последствия были нивелированы достаточно быстро. За период с 2014 по 2018 гг. нефинансовые организации из санкционного списка увеличили долю займов в рублях с 13 до 41\%, а рублевых облигаций приблизительно с 40 до 66\% [1].

Увеличение облигаций в структуре совокупного долга российских компаний из санкционного списка происходило параллельно увеличению масштабов отечественного рынка облигаций и росту спроса на них со стороны российских инвесторов. Так в первом квартале 2018 г. примерно 40\% всех займов крупных российских корпораций было обеспечено эмиссией облигаций. C тех пор данная тенденция укрепляется. Коммерческие банки, попавшие под санкции, напротив, сократили долю облигаций в обязательствах с 6 до 4\%, поскольку в банковской системе образовался структурный профицит ликвидности, а обращение облигаций в долларах и евро сократилось с 38 до 31\% [7].

Только что был опубликован рейтингом РБК 500 [8]. В рейтинг вошла 401 частная компания (394 в 2018 году), 81 компания, контролируемая государством (88 в 2018 году), семь с госкон- тролем и иностранным участием, семь частных компаний со значительным участием государства и четыре частные компании со значительной долей иностранного владения. Выручка этих компаний в 2018 г. росла в два с лишним раза быстрее, чем годом ранее (18,2 против 9\%). Пятерка лидеров осталась неизменной уже пятый год. Это «Газпром», ЛУКОЙЛ, «Роснефть», Сбербанк и РЖД. В топ-10произошли незначительные изменения: ВТБ перебрался с шестой строчки на восьмую, уступив место «Сургутнефтегазу», а «Росатом» поднялся с 13-го места на десятое, потеснив «Россети».Подавляющее большинство лидеров представлены сырьевыми компаниями и госкорпорациями, а не представителями «новой экономики», типа «Яндекса» и «Лаборатории Касперского».

Совокупная выручка 500 крупнейших компаний России составила 85,5трлн. руб. Общая выручка участников рейтинга оказалась на $18,2 \%$ больше, чем годом ранее (72,3 трлн. руб.). $82,3 \%$ составляет отношение совокупной выручки РБК 500 к размеру ВВП России в 2018 году (103,9 трлн. руб. в текущих ценах). Годом ранее это отношение равнялось 78,5\%.Суммарный рост выручки компаний - участниц рейтинга РБК 500 года составил $20,1 \%$, а ее органический рост, если считать по компаниям, которые участвуют в рейтингах предыдущих лет - 19\%.

Четвертый год подряд самым прибыльным в рейтинге становится «Газпром». Его акционеры получили более 1,5 трлн. руб. прибыли. Примечательно, что прибыль «Газпрома» близка по значению с объемом выручки X5 Retail Group, занимающей седьмую позицию РБК 500. Самой убыточной компанией рейтинга стал ВЭБ.РФ (ранее Внешэкономбанк), его убыток составил 172,3 млрд. руб. На втором месте - «Ямал СПГ». Компания показала убыток 157,7 млрд. руб. Примечательно, что она заняла второе место по росту выручки.

Если рассматривать распределение прибыли и убытков по отраслям, то 52,9\% прибыли получены компаниями нефтегазового сектора $-4,9$ трлн. руб. На втором месте - финансовый сектор с совокупной прибылью в 1,6 трлн. руб. и долей $17,2 \%$.На долю горно-металлургических компаний приходится $13,4 \%$ прибыли участников рейтинга, или 1,2 трлн. руб. Доли в общей прибыли остальных отраслей не превышают 3\% по каждой из них.32,1\% убытка пришлось на финансовый сектор. Финансовые компании и бан- 
ки потеряли за год 224 млрд. руб. Из них 172,3 млрд. - это убыток ВЭБ.РФ.

Второе место по доле в совокупном убытке заняла нефтегазовая отрасль, тут компании потеряли 203,6 млрд. руб. Это 29,2\% от совокупного убытка компаний рейтинга. Размер активов указали в РБК 500409 компаний (412 годом ранее). Совокупный размер известных активов участников рейтинга составил 192,5 трлн. руб. Лидером по размеру активов среди раскрывших этот показатель пятый год подряд стал Сбербанк (31,2 трлн. руб. на конец года). В топ-10 по активам попали пять компаний финансового сектора, четыре нефтегазовые и одна из транспортной отрасли (РЖД).

Нельзя назвать санкции ключевым сдерживающим фактором в экономическом росте России на среднесрочную перспективу. В исследовании АКРА [2] за период с 2017 по 2018 гг потенциал роста экономики страны оценивался в $1,5 \%$, и фактический показатель уже близок к этому уровню. В частности рост сдерживался за счет сокращения численности рабочей силы (это негативный эффект с точки зрения темпов экономического роста, который по оценкам АКРА, составлял -0,4 п.п. в 2018, и сохранится до 2020 г.). Поэтому, среднесрочный рост экономики (в случае отмены санкций) вряд ли бы существенно усилился. Темпы роста в долгосрочной перспективе могут оказаться более ощутимыми как для компаний, таки для экономики в целом за счет влияния санкций. Если бы санкционный режим отсутствовал, то основные барьеры для более быстрого роста, которые были бы возможны, - это отмена совместных технологических проектов, снижение экспорта алюминия и добычи нефти и газа.

Введенные санкции в 2014-2015 годах по целому ряду долгосрочных проектов, связанных с освоением новых нефтяных месторождений - отменены. Это затронуло девять крупных совместных проектов ExxonMobil и ПАО «Роснефть». Если для ExxonMobil это означало потерю своих инвестиций, то для ПАО «Роснефть»- поиск новых партнеров и инвесторов. Ограничения, введенные в 2014 году на нефтегазовые компании, скажутся на показателях добычи нефти в 2020-х. Эксплуатация месторождений, начавшаяся после 2013 года должна поспособствовать увеличению общего объема как технологических, так и инвестиционных стимулов для зрелых, и новых месторождений.
Конечно, данный процесс потребует существенных затрат, но будет сдерживаться из-за существующих санкций. Несмотря на запрет экспорта в Россию различных видов оборудования, в свою очередь, дал положительный импульс развитию внутри страны как для энергетического машиностроения, так и для производства нефтегазового оборудования.

Достаточно сложная ситуация в связи с санкциями сложилась у компании UCRusal, который вынужден сократить объем экспорта алюминия в США из России более чем на $10 \%$. Ситуация осложняется тем, что рост продаж алюминия на российском рынке не высоки. Если даже удастся увеличить этот показатель 3-4\% в связи с изменением стандартов для алюминиевой продукции, то это не позволит компенсировать эффект сокращения экспортных поставок алюминия в западные страны. В какой-то мере можно надеяться на сокращение негативного влияния западных санкций на компанию UCRusal в связи с потенциалом расширения экспортных контрактов на поставку алюминия в Китай.

Прогнозируя вполне благоприятные итоги 2019 года, эксперты утверждают, что, несмотря на рост выручки, российский бизнес не спешит инвестировать ее в производственные проекты, а предпочитает размещать средства на банковских депозитах. Это объясняется главным фактором экономической неопределенности будущего российской и глобальной экономики. Это не позволяет корректно оценить доходность долгосрочных проектов, а также ограничения внутреннего спроса. Во многом это является серьезным препятствием на пути выполнения национальных проектов в России, которые рассматриваются в качестве реальных драйверов экономического роста в среднесрочной перспективе.

Таким образом, оценивая негативное влияние антироссийских санкций, их нельзя отнести к ключевым сдерживающим факторам, тормозящим рост российских компаний в обозримой перспективе. Главной причиной их относительно низких темпов роста являются структурные факторы типа сокращения численности рабочей силы, отсутствия необходимых инвестиций в экономику, профессионального гэпа и недостатков системы образования в контексте учета ею требований инклюзивного развития России и потребностей знаниеёмкой экономики будущего и т.п. Другими словами, никакие санкции и их 
негативное влияние нельзя сравнить с архиважностью назревших структурных изменений российской экономики. В этой связи целесообразно было бы воспользоваться западными санкциями для целей стимулирования российских промышленных гигантов осуществить наконец стратегическую переориентацию их экономической деятельности с внешних факторов развития, на приоритетное использование инклюзивного потенциала роста самой России.

\section{Библиографический список}

1. Е. Базанова. Угрозы российской экономики создают сами власти, предупреждает S\&P // Ведомости. 2018.23. июля.URL: https://www.vedomosti.ru/economics/articles /2018/07/23/776198 -ugrozi-rossiiskoi-ekonomike (дата обращения: 20.09.2019)

2. В.Баранова, Н. Прохорова Изменение экономической политики - основной канал влияния санкций на российскую экономику [Электронный ресурс] // Исследование AKPA. 2018. 10 июля.URL: https://www.acraratings.ru/research/819(дата обращения: 20.09.2019)

3. Покрамович О.В. Технологии корпоративного обучения: новые перспективы развития //Теория и практика сервиса: экономика, социальная сфера, технологии. - 2018. - № . 2 (36). С. 28-30

4. Портанский А.П. Антироссийские санкции-меры деструктивные и контрпродуктивные //Деньги и кредит. - 2014. - № . 10.- С. 8-10

5. Итоги десятилетия 2008-2017 годов в российском банковском секторе: тенденции и факторы. Серия докладов об экономических исследованиях. Банк России. Июнь 2018. № 31URL: https://cbr.ru/ec_research/ (дата обращения: 20.09.2019)

6. Среднесрочный прогноз Банка России по итогам заседания Совета директоров по ключевой ставке 22 марта 2019 годаURL: https://cbr.ru/Collection/Collection/File/16778/forecast_190322.pdf (дата обращения: 20.09.2019)

7. Обзор финансовой стабильности. Информационно-аналитические материалы Банка России. 2018. № 1 URL: https://cbr.ru/publ/stability/ (дата обращения: 20.09.2019)

8. http://top.rbc.ru/economics/18/05/2014/924411.shtml. 